\title{
Strategic Analysis on Green Operation of Medium-Small Firms in Jiangsu Province
}

\author{
Jia Sun, Jianping Wu, Qingjun Meng \\ Business School, Hohai University, Nanjing, China \\ Email: SUNJIA361@163.com
}

Received June 2014

\begin{abstract}
Green operation is an important part for Medium-Small enterprise taking the sustainable development path. It requires enterprises to undertake environmental protection and social responsibility actively. Although green operation is limited by enterprise capital and technology, it is conducive to the harmonious unity of economic and environmental benefits. Enterprises' green operation is based on the attention to green brand and culture construction, related personnel training, developing green products, and reducing green operation costs. The government of Jiangsu Province attaches great importance to construct better environment for green operation of mediumsmall enterprise.
\end{abstract}

\section{Keywords}

Medium-Small Enterprise, Green Operation, Social Responsibility, Environmental Benefits, Economic Benefits

\section{Introduction}

More and more enterprises in Jiangsu Province attach importance to green operation. Large enterprises, due to technical and financial advantages, often develop better than medium-small enterprise. As an eastern coastal province of China, Jiangsu Province has relatively less resources while population increasing rapidly. Environmental capacity problems and the construction of ecological civilization result in more pressure for enterprises to implement green operation. It is also a key factor to promote economic development of Jiangsu. Enhancing the international competitiveness by green operation has become a necessary condition for enterprises' survival and development. Green operation refers to the whole process of environmental integration into enterprise management, as well as business activities of integrating environmental protection and business development [1]. Green operation is earlier than enterprise' green operation. With the rise of environmental awareness, the quality of living and the concept of green consumption are major considerations for consumers to choose products.

Chinese Government pays attention to enterprise' green operation. China’s State Council approved the "China National Implementation Plan of the Stockholm Convention to fulfill" to keep the promise in the protection of human health and ecological environment in April 2007. The government of Jiangsu Province formulated the "Implementation Opinions energy conservation work in Jiangsu Province" and other regulations. Enterprise' 
green operation requires that every aspect of business and management guidelines is based on environmental protection and solve environmental problems caused by business activities by realizing zero emissions of pollutants and recycling of resources. The core of enterprise' green operation is to regard the environmental protection as a fundamental link to corporate profit-making activities, which can result in the harmony and unity of corporate economic and environmental benefits. But there are still some enterprises, especially medium-small enterprises, to ignore green operation. It will bring the risk of corporate sustainability.

\section{Literature Review}

W. Hopfenbeck (1993) [2] proposed: green operation requires companies to establish operations in ecologybased policy, so that enterprises are not only beyond the mere pursuit of interests, but also in a dominant position in the competition. Green operation means taking measures to environmental issues in advance so that companies can avoid conflicts of economic interests and ecological environment in order to achieve harmony and unity of the two. Cao Lingqiu (2011) stressed that companies should establish green management plan based on business requirements as soon as possible in order to get comprehensive environmental benefits and reduce the pressure from society and government [3].

Li Jingjiang (2006) [4] also mentioned that the direct background for enterprise' green operation arising is that we are facing deteriorating global environment, and this deterioration, is mainly caused by economic activity of the human society. So it is necessary to make enterprise's green operation a vital part of the sustainable development strategy and understand problems from the height of corporate development strategy. The concepts mentioned in study of Chinese scholars include environmental management and green operation in addition to environmental operation and green operation. Economists in developed countries have also some theories on corporate green operation concepts. China took a step later whether in corporate green operation theoretical study or practical exploration. So, these theories still need improvement.

\section{System Science Theory and Its Applications}

\subsection{System Science Theory}

Bertalanffy was one of the earliest scholars to use this concept of System Science Theory. System Science Theory believes that the system is a collection of interrelated elements. It is based on an overall perspective to integrate various parts of the perceived object so that its purpose can be achieved [5]. System Science Theory has a unique value for analyzing green operation issues related to medium-small enterprises in Jiangsu Province. This theory believes that the system has a boundary, or a range. Similarly, there is also a "border" for enterprises' green operation. "Border" main elements are: corporations, governments, financial institutions, residents and other personnel (Figure 1). Theory also stressed that the system is composed of certain elements. There are complex ecological relationships just like competition, dependence and cooperation among these various system elements. There are similar relationships among these elements in green operation of enterprises. The purpose of enterprise's green operation is to maximize benefits from enterprise and economic environment. The system provides functionality services for environment, which is a positive role and enables output referred to "functional.” If there are ecological cooperation relationships among the elements within the system, the system can maintain normal speed operation overall long-term.

\subsection{Applications of System Science Theory}

\subsection{1. "Pressure" on the System from Environment}

System Science Theory believes that environment applies constraints, disturbance and pressure on the system

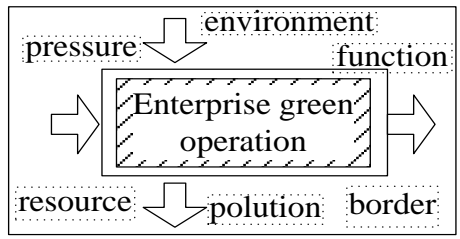

Figure 1. Environment of enterprise green operation. 
and even endangers the survival and development of system. It brings a negative effect and input, which is collectively referred to "pressure", such as social views or policies on the environment pollution and green operation. With the development of economy and the popular concept of circular economy, it becomes the future trend to integrate green operation concepts and methods in business management. Since the 1990s, a number of companies in developed countries have been a step ahead in implementing green operation. Green operation is a new idea arising in the background of global environment deteriorating, which is the inevitable choice for sustainable development. Only through changing the model from excessive exploitation of natural resources to green operation model based on their own survival and seeking changes in the business, social and environmental can we achieve the harmonious development of man and nature enterprises.

For years, our country takes an extensive development path with high input, high consumption and low efficiency, neglecting the problem of pollution and its governance. This model has come to an end. In the 21st century, the implementation of enterprise's green operation has become essential. And the government has gradually paid attention to environment and resources, released the "Environmental Protection Law", "Renewable Energy Law" and other laws or regulations, proposed path of sustainable development and implement the scientific development concept, vigorously developed the circular economy and stressed building a resource-saving society. So far from 2011, Nanjing has more than 400 "three high and two low" (high pollution, high energy consumption, high emission and low efficiency, low output) business remediation, closes more than 500 small boilers. There is a high proportion of medium-small enterprises. Taizhou city government issued the "Guiding Catalogue of Industrial Structure Adjustment in Taizhou City (2013 version), "the high-energy, pollution control and other projects included in the hard phase-out category. "Green credit" gradually plays a role to strengthen environmental protection in the enterprise. Such as, Suzhou obtains financial support, including the development of energy conservation, corporate restructuring and upgrading, green transportation and other green projects, including the National Development Bank.

\subsubsection{Environment "Contaminated" by the System}

Some internal elements have destructive and competitive activities to system environment, which belong to unfavorable output, collectively referred as the environmental "pollution". Such as, mineral resource recovery of many companies is very low, which results in a serious waste of resources. Because irrational economic structure, traditional resource use patterns have not fundamentally changed, it is common sacrificing the ecological environment for immediate and partial interests. The problem of high raw material consumption intensity of industrial production is prominent. Raw material consumption Strength is the raw material consumption per unit of gross domestic product in the proportion of consumption. It is an important indicator of the level of production and material consumption. Since 2013, some areas in China meet frequent severe fog and haze, closely related to the direct combustion of coal and automobile exhaust emissions. The proportion of heavy chemical in Nanjing is so large resulting in a great impact on the environment pollution.

The current national ecological environment situation is still grim. Many companies' pollutant emissions are chronically high, exceeding environmental self-purification capacity so far. Some of the watershed and urban air pollution is very serious. The extent of ecological damage in some areas is still increasing. Such as the Environmental Protection Commission of Jiangsu Province, the joint monitoring units to third parties - Nanjing Environmental Monitoring Station have found sewage waste-water phenomenon of excessive emissions in check, and as a provincial issues supervise the handling of cases [6]. With the rapid economic growth in recent years, China's ecological environment meets tremendous pressure. Environmental issues in a century industrialized countries constitute encountered in our 20 years quickly occurred. Because of the limitations of capital and technology, many small and medium enterprises have a bottleneck in controlling environmental pollution, especially the lack of core technologies and cost increases and other issues.

\section{Measures on Green Operation Strategy of Medium-Small Enterprise}

System Science Theory believes that "environment” provides the space, resources, incentives or other conditions needed for survival and development to the system. It is a positive role and enabling input, referred as "resources." By adjusting the input of resource, we can reduce the "pressure" and "pollution" to improve the system "function." By exerting a beneficial effect on small and medium enterprises green operation to promote effective operation of "system", the community will be able to form mutually beneficial cooperation and ecological relations in the economic and environmental benefits and other aspects. 


\subsection{Support of National Policy Should Be Strengthened}

A series of policies were proposed by our government to support green operation, such as increasing the financial input to agricultural industrialization, supporting training, base construction, asset restructuring, technological innovation, interest payments on loans for farmers provided by leading enterprises, in addition to building a agricultural industrialization investment and financing system for implementation of the industrialization of agriculture leading enterprises tax incentives. Such as the State "12th Five-Year Plan" comprehensive energy reduction program," "the State Council views on strengthening environmental protection priorities" and other macro-control policies, besides of "green credit guidelines" by China Banking Regulatory Commission in 2012 and "green credit rating and credit enterprises in Jiangsu Province Interim Measures" by Jiangsu provincial Environmental Protection Office and the United Provinces of credit [6]. Corporate income tax from enterprises engaged in agriculture, forestry, animal husbandry and fishery projects may be exempted or reduced. Service management should also be strengthened to create a relaxed and harmonious, good development environment and the formation of multi-propulsion force.

In order to achieve sustainable development of the national economy, China regards saving resources and environmental protection as a basic national policy. China also puts emphasis on building a resource-saving and environment-friendly society as a sustainable development strategy, vigorously strengthening resource management, promoting environmental protection and ecological construction. Our guidelines in the implementation of sustainable development strategy are: developing recycling economy, creating a resource-saving and environment-friendly society, promoting the harmony among economic development, population, resources and the environment. Essentially, circular economy is an ecological economy, which requires the organization of economic activity to form a "resources-products-renewable resources" feedback process. The process is characterized by low extraction, high utilization, low emissions, a reduction of its three principles, reuse and recycle. The core idea of sustainable development refers to the same economic development, protect resources and improve the environment, economic development can be sustained.

\subsection{Developing Concepts of Conserving Resources and Protecting the Environment}

The primary concepts for companies to implement green operation strategy is conserving resources, protecting the environment and pursuing sustainable development. Companies should increase investment to environmental protection projects, which are helpful to reduce the pollution. Under the increasingly fierce competition counterparts, companies pay attention to related research to protect environmental resources in a market economy. New products, new processes, new technologies are emerging. Green brand and green operation receive more attention, which are gradually integrated into the more long-term development strategy. Only by green innovation, can enterprises gain competitive advantages. With the change in people's attitudes, more and more people require green and healthy products. In order to meet consumer attitudes of the public, it is necessary to launch a series of green products for enterprises. In the future, enterprise will pay more attention to innovative technology, environmentally friendly and intensive direction.

There are many environmental protection activities with disappointing participation. Public participation is so vital for a good sale of green products. It is the basis for the successful implementation of green operation. Guiding public opinion is also very important. Many customers understand green brand through the media, newspapers, and so on. Consumers will consider consuming only after knowing the brand and building a certain understanding. Promoting corporate green culture is a very complex work throughout the whole process in business activities. It must be driven by managers. Enterprises should establish a green organization dedicated to promote green operation. Companies can establish a green management system in design and production, raw material procurement, product marketing behavior and other processes in order to achieve optimal economic efficiency and environmental benefits.

\subsection{Nurturing Talents with the Government, Universities and Other Organizations}

Since strength of medium-small enterprise is weaker than large enterprises, it is often difficult to attract or leave talents for them. How to train, introduce and play a "green operation talent" enthusiasm for innovation is important in order to improve the capability of independent innovation. Enterprise green operation talents means talents concerned with environmental protection, marketing, management, technology and other related aspects. It 
involves environmental protection, energy conservation and waste disposal in merely technical aspect. It is necessary to change economic growth driven by increased consumption of resources to scientific and technological progress, improving the quality of workers, innovation in management. We must deepen reform and innovation to get rid of the shackles of ideas and institutional barriers for providing talent development with a strong guarantee. "Green management talent" will be favored by the market who are engaged in environmental technology, new energy, new materials, environmental consulting and environmental services, etc.

The basic premise and fundamental purpose of economic and social development both are human development. For solving the imbalance in China's economic development, uncoordinated and unsustainable ecological pressure on the environment and other issues, we must implement science and education strategy and talents strategy in depth. Education has the priority to develop. There are still misunderstanding in vocational education and vocational skills talents. At present, enterprises are lack of high-quality compound green operation talents with a global vision. In this regard, by exchanges among government, industries, academics, researches, it is conducive to the realization of the complementary strengths of each organization's resources and can cultivate talents who understand medium-small green operation.

\subsection{Development of Green Products to Reduce Costs of Green Operation}

Only by adapting to market demand, keeping innovation, developing with intensive production methods can medium-small enterprises obtain market recognition in competition with large enterprises, such as having emphasis on environmental protection and new energy industries. In face of green market, enterprises should rapidly change business direction and develop green products to occupy the market quickly. Enterprises should set up specialized agencies to collect information for green market segmentation analysis, thereby finding out the operation and development strategies with green market positioning. Cost management is a so important that it is directly related to the production and development. Enterprises should reduce costs to improve economic efficiency and competitiveness. Products or services with high-quality and low-cost can attract more users.

It is necessary to implement cost management system if medium-small enterprise hoping to stand out in the fierce competition. Cost management system can help reduce costs, improve the level of economic management, the economic efficiency, enterprise competitiveness and cost-conscious corporate employees. With the development of market economy and the implementation of commercial credit, many companies increase accounts receivable, which is important in current asset management. The main reason is the credit receivables generated. By providing convenience to customers through credit, companies can promote the sales and market share. Credit is more important for companies develop new products or new markets. In favorable credit conditions, corporate managers should make the right decision between increased compensation and credit costs.

\section{Conclusion}

\subsection{A Good External Condition Is Needed}

Medium-small enterprise in Jiangsu Province requires a good external condition conducive to implement green operation. External environment includes the legal environment, policy environment and the social environment. Legal environment represents the legislative and judicial environment to constraint corporate behaviors on environment destruction and pollution. Policy environment refers to policy measures to guide enterprises to promote environmental protection, mainly in the economic benefits and constraints. And social environment means the community participating in environmental protection actively, as well as the constraints, oversight and coordination to the implementation of green operation operations.

\subsection{The Change of Concept Is Necessary}

The primary concepts and basic ideas of medium-small enterprises in Jiangsu Province to implement green operation strategy is taking conserving resources, protecting environment and pursuing sustainable development into consideration. We should put emphasis on research and take measures to protect resources. Specific implementation of green operation strategy involves green entrepreneurial spirits, green values, green operation ideas, green regulations, green and cultural life. However, it will affect the decisions of managers and staff attitudes to promote the enterprise green operation strategy. It is difficult to meet investment in green operation needs due to the limited strength of medium-small enterprises, such as lack of capital and technology. 


\subsection{Improving Operations to Meet the Financial Conditions Are Feasible}

Deficiencies exist in innovative products to serve green operation from Jiangsu Province financial institutions. Due to credit risks, role of "green credit" needs to be strengthened. Financial industries should give priority to pollution-free industries just like tourism. If the firm meets "Jiangsu Province corporate environmental credit evaluation criteria and evaluation methods" and it was rated as "green" firm, it is possible to obtain preferential lending rates and insurance agencies to reduce environmental pollution liability insurance rates. Otherwise, environmental protection departments will delay matters about listing, financing and other environmental auditing. Companies should have comprehensive analysis of the financing risks and benefits, according to their own conditions, government support for green credit and attitude of financial markets.

\section{Acknowledgements}

We acknowledge financial support from the Key Project of Philosophy and Social Science Research in Colleges and Universities of Jiangsu Provincial Education Department (NO.2010ZDIX M004) and the National Undergraduate Training Programs for Innovation and Entrepreneurship in Hohai University (NO.201205XCY007).

\section{References}

[1] Shen, Y.L. (2010) Gorgeous Green Operation of Chinese Enterprises. Enterprise Herald, 12, 60-61.

[2] Ju, F.H. (2008) Firms Green Duty and Strategy—-Theory, Methods and Practice. Zhejiang University Press, Hangzhou.

[3] Cao, L.Q. (2011) Research on Firms Green Operation Entities Screening and Combination. Explorations.

[4] Li, J.J. (2006) Firms Green Operation—Sustainable Development Road. Tsinghua University Press, Beijing.

[5] Miao, D.S. (1998) Essentials of Systems Science. Third Edition, China Renmin University Press, Beijing. 